\title{
Electroacupuncture and splinting versus splinting alone to treat carpal tunnel syndrome: a randomized controlled trial
}

\author{
Vincent C.H. Chung PhD, Robin S.T. Ho MPH, Siya Liu MPH, Marc K.C. Chong PhD, Albert W.N. Leung PhD, \\ Benjamin H.K. Yip PhD, Sian M. Griffiths DSc, Benny C.Y. Zee PhD, Justin C.Y. Wu MD, Regina W.S. Sit MBBS, \\ Alexander Y.L. Lau MBChB, Samuel Y.S. Wong MD
}

\begin{abstract}
Background: The effectiveness of acupuncture for managing carpal tunnel syndrome is uncertain, particularly in patients already receiving conventional treatments (e.g., splinting). We aimed to assess the effects of electroacupuncture combined with splinting.

Methods: We conducted a randomized parallel-group assessor-blinded 2-arm trial on patients with clinically diagnosed primary carpal tunnel syndrome. The treatment group was offered 13 sessions of electroacupuncture over 17 weeks. The treatment and control groups both received continuous nocturnal wrist splinting.
\end{abstract}

Results: Of 181 participants randomly assigned to electroacupuncture combined with splinting $(n=90)$ or splinting alone $(n=$ 91), $174(96.1 \%)$ completed all follow-up. The electroacupuncture group showed greater improvements at 17 weeks in symptoms (primary outcome of Symptom Severity Scale score mean difference [MD] $-0.20,95 \%$ confidence interval $[\mathrm{Cl}]-0.36$ to -0.03 ), disability (Disability of Arm, Shoulder and Hand Ques- tionnaire score $\mathrm{MD}-6.72,95 \% \mathrm{Cl}-10.9$ to -2.57), function (Functional Status Scale score $\mathrm{MD}-0.22,95 \% \mathrm{Cl}-0.38$ to -0.05$)$, dexterity (time to complete blinded pick-up test MD -6.13 seconds, $95 \% \mathrm{Cl}-10.6$ to -1.63$)$ and maximal tip pinch strength (MD $1.17 \mathrm{lb}, 95 \%$ $\mathrm{Cl} 0.48$ to 1.86 ). Differences between groups were small and clinically unimportant for reduction in pain (numerical rating scale $-0.70,95 \% \mathrm{Cl}-1.34$ to -0.06 ), and not significant for sensation (first finger monofilament test $-0.08 \mathrm{~mm}, 95 \% \mathrm{Cl}-0.22$ to 0.06 ).

Interpretation: For patients with primary carpal tunnel syndrome, chronic mild to moderate symptoms and no indication for surgery, electroacupuncture produces small changes in symptoms, disability, function, dexterity and pinch strength when added to nocturnal splinting. Trial registration: Chinese Clinical Trial Register no. ChiCTR-TRC-11001655 (www. chictr.org.cn/showprojen.aspx?proj=7890); subsequently deposited in the World Health Organization International Clinical Trials Registry Platform (apps.who.int/trialsearch/Trial2. aspx?TrialID=ChiCTR-TRC-11001655).
$\mathrm{P}$ rimary carpal tunnel syndrome is one of the most common forms of peripheral entrapment neuropathy, ${ }^{1}$ with an estimated prevalence of $2.7 \%$ in the general population. ${ }^{2}$ It is a major cause of disability in the upper extremity, ${ }^{3}$ incurring considerable limitation on daily activities among patients. ${ }^{4}$ As a workrelated disorder, carpal tunnel syndrome carries significant economic impact and often leads to compensation claims. ${ }^{5}$ For patients with mild to moderate carpal tunnel syndrome without evidence of median nerve denervation, nocturnal wrist splinting or local steroid injection are 2 conservative treatments commonly recommended in primary care practice. ${ }^{6}$ Splinting is often used as first-line treatment in primary care, ${ }^{7-9}$ but a Cochrane review reported that splinting only slightly improved symptom scores for carpal tunnel syndrome at 4 weeks. ${ }^{10}$ For steroid injection, a Cochrane review showed that steroid injection was superior to placebo injection in improving symptoms at 4 weeks, but longer term effect beyond 12 weeks was uncertain. ${ }^{11}$ A recent randomized controlled trial (RCT) also showed that steroid injection provided more benefits than placebo at the 10th week of treatment, but there was no significant difference observed at 1-year follow-up. ${ }^{12}$ Only one-third of patients with carpal tunnel syndrome who received steroid injections had longer term benefits ${ }^{13}$ and some required an additional 2-3 injections to obtain relief. ${ }^{13}$ However, 1 study conducted in Estonia reported that patients who received repetitive steroid injections were more likely to
Competing interests: None declared.

This article has been peer reviewed.

Accepted: Mar. 15, 2016 Online: June 6, 2016

Correspondence to: Vincent Chung, vchung@ cuhk.edu.hk

CMAJ 2016. DOI:10.1503/ cmaj.151003 
have postoperative symptoms of carpal tunnel syndrome if they eventually opted for surgery. ${ }^{14}$

Acupuncture is commonly used to manage pain and neuropathy in Chinese medicine. A systematic review published in 2011 included 2 trials that compared acupuncture and steroid injection; acupuncture was found to be slightly better in reducing symptoms of carpal tunnel syndrome. ${ }^{15}$ A randomized trial $(n=77)$ published in 2009 reported that patients receiving acupuncture treatment showed more improvement than those taking low-dose prednisolone orally. ${ }^{16}$ However, another trial that compared acupuncture with splinting reported no significant difference between them. ${ }^{17}$ Among controlled trials of sham acupuncture, 1 small randomized trial reported no significant symptom improvement, ${ }^{18}$ but another trial suggested that there was symptom improvement. ${ }^{19}$ These conflicting results do not provide clear evidence of the value of adding acupuncture to splinting in primary care settings.

Electroacupuncture is a technique in which a weak electric current is passed between 2 needles. We chose electroacupuncture because results from previous clinical trials and systematic reviews had suggested that it might be more effective in relieving pain than standard manual acupuncture..$^{20}$ These results have been attributed to the ablility of electroacupuncture to block pain by activating a variety of bioactive chemicals through peripheral, spinal and supraspinal mechanisms. ${ }^{21}$ Therefore, we conducted a randomized trial to compare electroacupuncture combined with nocturnal splinting with nocturnal splinting alone for patients with carpal tunnel syndrome.

\section{Methods}

\section{Trial design}

We conducted a prospective randomized parallel group trial over 17 weeks. Enrolment started in January 2013, and follow-up was completed in April 2014.

\section{Setting and participants}

We advertised at various primary care clinics, in local newspapers and on social media. Respondents were examined by trial investigators and screened for eligibility at a family medicine teaching clinic of the Chinese University of Hong Kong. All electroacupuncture treatment was performed at this centre.

\section{Inclusion criteria}

To confirm their eligibility, we invited patients to fill in the Katz hand diagram questionnaire ${ }^{22-25}$ under the guidance of a clinician.
Patients aged 18-70 years with primary idiopathic carpal tunnel syndrome who fulfilled the following criteria were included: satisfying classic or probable criteria for carpal tunnel syndrome by Katz hand diagram (tingling or numbness in $\geq 2$ of 4 radial fingers), ${ }^{26}$ positive in at least 2 of 3 clinical tests (i.e., Phalen maneuver test, Tinel sign test, and the wrist flexion and median nerve compression test), ${ }^{27}$ able to respond to questionnaires in Cantonese and able to provide written informed consent.

\section{Exclusion criteria}

We excluded patients with symptoms and signs suggestive of median nerve denervation with axonal loss, including thenar muscular atrophy or weakness, or persistent numbness. ${ }^{28} \mathrm{We}$ also excluded patients with secondary carpal tunnel syndrome owing to coexisting polyneuropathy, inflammatory arthropathy, pregnancy, diabetes mellitus, hypothyroidism, malignancy, rheumatoid arthritis, alcoholism, infections, spaceoccupying lesions (tumours, hypertrophic synovial tissue, fracture callus and osteophytes) and familial neuropathy. ${ }^{29}$ Patients who had previous carpal tunnel release surgery, who were taking oral steroids or warfarin, who had received treatment with local steroid injections or acupuncture for carpal tunnel syndrome, or patients with other serious diseases requiring inpatient care were also considered ineligible. Patients with cervical radiculopathy were also excluded (see details in Appendix 1, available at www.cmaj.ca/lookup/suppl/doi:10.1503/ cmaj.151003/-/DC1. We did not perform a nerve conduction study to confirm the diagnosis, according to the current standard of primary care practice.

\section{Randomization and interventions}

After we confirmed eligibility and obtainedwritten informed consent, block randomization was applied to allocate patients to the electroacupuncture with nocturnal splinting (treatment) group and the nocturnal splinting only (control) group in a 1:1 ratio. We used the Random Allocation Software random block sizes option and did not prespecify the block size range..$^{30,31} \mathrm{We}$ used a sequentially numbered procedure with opaque sealed envelopes to conceal the random sequence. ${ }^{32}$ The sequence was generated and concealed by a trained research assistant, independent of the study, who was supervised by one of the authors (S.L.).

Patients who were randomly assigned to the electroacupuncture with splinting group received a prefabricated wrist splint (Medex Carpal Tunnel Splint W09) with neutral posi- 
Table 1: Participant characteristics at baseline

\begin{tabular}{|c|c|c|}
\hline Characteristic & $\begin{array}{l}\text { Treatment group } \\
\text { (electroacupuncture } \\
\text { with splinting at } \\
\text { night) } \\
n=90\end{array}$ & $\begin{array}{c}\text { Control group } \\
\text { (splinting at night only) } \\
n=91\end{array}$ \\
\hline Age, yr; mean $\pm S D$ & $51 \pm 10.2$ & $51 \pm 8.7$ \\
\hline Female, $n(\%)$ & 77 (86) & $81(89)$ \\
\hline \multicolumn{3}{|l|}{ Education level, $n(\%)$} \\
\hline Primary or below & $7(8)$ & $10(11)$ \\
\hline Secondary & $60(67)$ & $56(62)$ \\
\hline Tertiary* or above & $23(26)$ & $25(27)$ \\
\hline Employed, $n(\%)$ & $51(57)$ & $59(65)$ \\
\hline \multicolumn{3}{|l|}{ Duration of symptoms, $n(\%)$} \\
\hline$>1 \mathrm{yr}$ & 69 (77) & $59(65)$ \\
\hline$\leq 1 \mathrm{yr}$ & $21(23)$ & $32(35)$ \\
\hline Duration of symptoms, mo; mean \pm SD & $50 \pm 52.7$ & $51 \pm 59.9$ \\
\hline Had treatment for the dominant hand, $n(\%)$ & 70 (78) & $73(80)$ \\
\hline \multicolumn{3}{|l|}{ Smoking status, $n(\%)$} \\
\hline Currently smoke & $4 \quad(4)$ & $3 \quad(3)$ \\
\hline Smoked previously & $5 \quad(6)$ & $1 \quad(1)$ \\
\hline Passively smoke & $19(21)$ & 17 (19) \\
\hline \multicolumn{3}{|l|}{ Alcohol consumption, $n(\%) \dagger$} \\
\hline Do not drink & $21(23)$ & $21(23)$ \\
\hline 1-9 drinks/wk & $69(77)$ & $68(75)$ \\
\hline$\geq 10$ drinks/wk & $0 \quad(0)$ & $2(2)$ \\
\hline Splint compliance during the trial, $\%$; mean \pm SD $\neq$ & $82 \pm 24$ & $85 \pm 21$ \\
\hline \multicolumn{3}{|l|}{ BCTQ score, mean \pm SD $\S$} \\
\hline SSS (range $1-5$ ) & $2.32 \pm 0.62$ & $2.40 \pm 0.69$ \\
\hline FSS (range 1-5) & $1.91 \pm 0.68$ & $1.99 \pm 0.74$ \\
\hline DASH score (range 0-100), mean \pm SD§ & $33.2 \pm 16.8$ & $34.5 \pm 18.9$ \\
\hline NRS for pain intensity (range $0-10$ ), mean \pm SD§ & $4.38 \pm 2.62$ & $4.52 \pm 2.78$ \\
\hline \multicolumn{3}{|l|}{ SWMT diameter, $\mathrm{mm}$; mean \pm SD } \\
\hline Thumb & $3.72 \pm 0.54$ & $3.60 \pm 0.53$ \\
\hline First finger & $3.61 \pm 0.49$ & $3.48 \pm 0.52$ \\
\hline Middle finger & $3.61 \pm 0.52$ & $3.53 \pm 0.51$ \\
\hline Little finger & $3.40 \pm 0.48$ & $3.43 \pm 0.47$ \\
\hline \multicolumn{3}{|l|}{ Time to complete DMMPUT, s; mean \pm SD** } \\
\hline Not blinded & $21.2 \pm 9.3$ & $22.3 \pm 13.6$ \\
\hline Blinded & $45.4 \pm 20.1$ & $45.3 \pm 18.4$ \\
\hline Tip pinch strength, lb; mean $\pm S D * *$ & $8.00 \pm 3.43$ & $8.29 \pm 3.62$ \\
\hline \multicolumn{3}{|c|}{$\begin{array}{l}\text { Note: BCTQ = Boston Carpal Tunnel Questionnaire, DASH = Disabilities of the Arm, Shoulder and Hand Questionnaire, DMMPUT = } \\
\text { Dellon-modified Moberg pick-up test, FSS = Functional Status Scale, NRS = numeric rating scale, SSS = Symptom Severity Scale, } \\
\text { SWMT = Semmes-Weinstein Monofilament Test. } \\
\text { *Tertiary education refers to all postsecondary education including, but not limited to, universities. } \\
\text { tOne standard drink corresponds to } 150 \mathrm{~mL} \text { of wine, } 355 \mathrm{~mL} \text { of beer or } 44 \mathrm{~mL} \text { of spirits. } \\
\text { fPatient compliance for splinting was defined as (total no. of nights that splints were worn)/(total no. of nights across duration of trial } \\
\times 100 . \text { Patients from both groups had similar high compliance rates for wrist splinting, and there was no significant difference } \\
\text { between groups. It is unlikely that such a slight variation in compliance for wrist splinting would have had an impact on outcomes. } \\
\text { Therefore, we did not consider this variation in the analysis of covariance reported in Table } 2 \text {. } \\
\text { \$A higher rating indicates greater severity. } \\
\text { I|Sensation in each finger was evaluated using } 5 \text { monofilaments of increasing diameter (i.e., } 2.83 \text { (best), 3.61, 4.31, } 4.56 \text { and } \\
6.65 \text { ). Mean diameter values for cutaneous sensation were reported and a decrement indicates improvement. } \\
\text { **Mean values were calculated by averaging results from } 3 \text { attempts by each participant. }\end{array}$} \\
\hline
\end{tabular}


tioning. ${ }^{33}$ In addition, these patients were given a 10-minute structured education by the investigator about the use of splints. ${ }^{34}$ Patients were asked to use the splint every evening for 8 hours during the study period. ${ }^{35}$ Patients with symptoms in both hands were offered bilateral splinting. The electroacpuncture protocol can be found in Appendix 1.

Patients assigned to the splinting only group received splints and the structured education as for the electrouncture group. These patients were registered on a waiting list and were offered electroacupuncture treatment after their last follow-up visit at week 17 as a form of compensation. In both groups, all participants had the expectation of receiving electroacupuncture, because the study procedures were explained to all potential participants before enrolment.

\section{Outcomes}

As recommended by the American Academy of Orthopaedic Surgeons, ${ }^{36}$ we used the Symptom Severity Scale of the Boston Carpal Tunnel

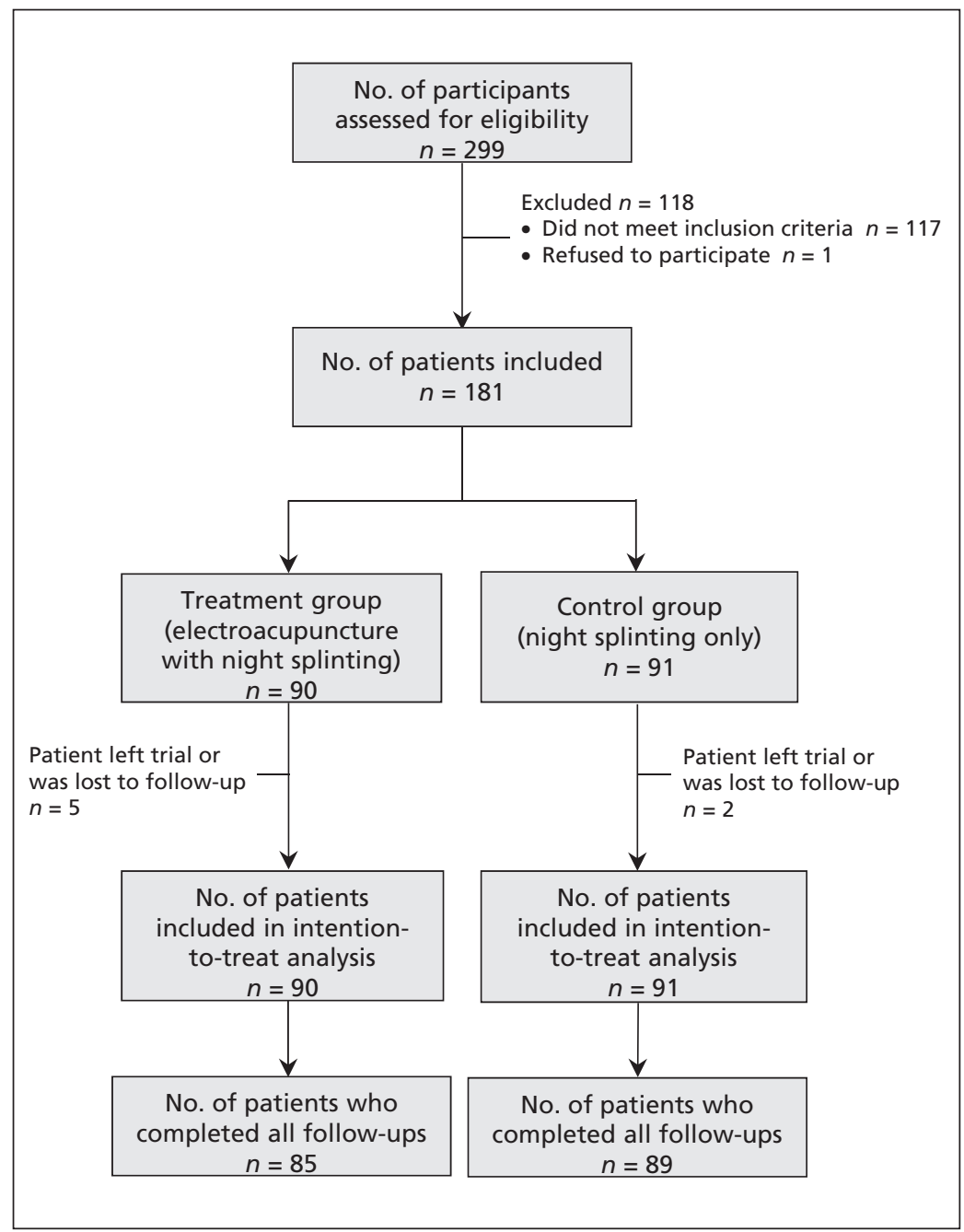

Figure 1: Participant recruitment flow diagram.
Questionnaire $^{37}$ as the primary outcome. In this scale, a summary score of 1 to 5 is obtained, with a higher score indicating greater symptom severity. ${ }^{38}$ Secondary outcomes were Functional Status Scale of the Boston Carpal Tunnel Questionnaire, ${ }^{37}$ Disabilities of the Arm, Shoulder and Hand (DASH) Questionnaire, ${ }^{39}$ pain intensity measured using the numeric rating scale, sensation measured using the SemmesWeinstein monofilament test, dexterity meassured using the Dellon-modified pick-up test and maximal tip pinch strength. We monitored adverse events related to electroacupuncture and splinting using a previously published approach. ${ }^{40}$ Details of outcomes and measurement methods for adverse events can be found in Appendix 1.

\section{Statistical analysis}

We employed double entry to all study data and applied appropriate data cleaning to ensure data quality. All eligible patients were included and randomly assigned in the primary analysis, based on the intent-to-treat principle. Appendix 2 (available at www.cmaj.ca/lookup/suppl/doi:10.1503/ cmaj.151003/-/DC1) provides details about estimation of sample size, statistical analyses, minimally important differences (MIDs) for each outcome and the application of cumulative distribution functions for data presentation.

\section{Ethics approval}

The trial was approved by the Joint Chinese University of Hong Kong - New Territories East Cluster Clinical Research Ethics Committee (CRE-2010.379).

\section{Results}

A total of 181 participants were randomly assigned to this trial. Ninety participants were assigned to the treatment group (electroacupuncture combined with splinting) and 91 were assigned to the control group (splinting at night only). All patients provided baseline data, and characteristics of the 2 groups were generally similar (Table 1). All patients were included in the intention-to-treat analysis. We defined a patient as having dropped out of the trial if they did not complete assessment at week 17. Five patients dropped out of the treatment group, and those patients who completed the trial achieved $100 \%$ and $82 \%$ compliance to treatment with electroacupuncture and splinting, respectively. Two patients dropped out of the control group, and those patients who completed the trial had a compliance rate to treatment with splinting of $85 \%$. None of the 
patients in the splinting treatment group received electroacupuncture treatment for carpal tunnel syndrome during the 17-week follow-up period. Figure 1 shows how patients were recruited and the reasons for patient exits from the trial. Main results for all outcomes are shown in Table 2. Recruitment started in January 2013, and the last follow-up was conducted in April 2014. Less than 1\% of the data were missing and were imputed.

\section{Primary outcome}

For Symptom Severity Scale score at week 5 and week 17 of the trial, patients in the electroacupuncture combined with splinting treatment group improved more than those in the splinting treatment only group (Table 2). The mean change in Symptom Severity Scale score from baseline to week 17 was -0.25 (95\% CI -0.37 to -0.12 ) in the electroacupuncture combined with splinting treatment group and -0.09

Table 2: Outcomes, by follow-up time

\begin{tabular}{|c|c|c|c|c|}
\hline \multirow[b]{2}{*}{ Outcome } & \multicolumn{2}{|c|}{ Change from baseline, mean $(95 \% \mathrm{Cl})$} & \multirow[b]{2}{*}{$\begin{array}{l}\text { Change in score, } \\
\mathrm{MD}(95 \% \mathrm{Cl})^{*}\end{array}$} & \multirow[b]{2}{*}{$p^{*}$} \\
\hline & $\begin{array}{l}\text { Treatment group } \\
\text { (electroacupuncture } \\
\text { with nocturnal } \\
\text { splinting) }\end{array}$ & $\begin{array}{c}\text { Control group } \\
\text { (nocturnal splinting } \\
\text { only) }\end{array}$ & & \\
\hline \multicolumn{5}{|l|}{ ВСTQ score } \\
\hline \multicolumn{5}{|l|}{ SSS } \\
\hline Week 1 & $0.04 \quad(-0.03$ to 0.12$)$ & $0.01(-0.08$ to 0.10$)$ & $0.02(-0.09$ to 0.13$)$ & 0.8 \\
\hline Week 2 & $-0.01 \quad(-0.09$ to 0.07$)$ & $-0.02(-0.13$ to 0.08$)$ & $-0.01 \quad(-0.13$ to 0.11$)$ & 0.9 \\
\hline Week 5 & $-0.17(-0.28$ to -0.06$)$ & $-0.06(-0.19$ to 0.07$)$ & $-0.15(-0.29$ to -0.01$)$ & 0.04 \\
\hline Week 17 & $-0.25(-0.37$ to -0.12$)$ & $-0.09(-0.25$ to 0.06$)$ & $-0.20(-0.36$ to -0.03$)$ & 0.02 \\
\hline \multicolumn{5}{|l|}{ FSS } \\
\hline Week 1 & $0.14 \quad(0.05$ to 0.23$)$ & 0.09 (0.00 to 0.18$)$ & $0.05(-0.08$ to 0.17$)$ & 0.5 \\
\hline Week 2 & $0.11 \quad(0.00$ to 0.22$)$ & $0.07 \quad(-0.04$ to 0.17$)$ & $0.03(-0.12$ to 0.17$)$ & 0.7 \\
\hline Week 5 & $-0.01 \quad(-0.12$ to 0.11$)$ & $0.06(-0.07$ to 0.18$)$ & $-0.09(-0.24$ to 0.06$)$ & 0.3 \\
\hline Week 17 & $-0.16(-0.28$ to -0.04$)$ & $0.02(-0.13$ to 0.17$)$ & $-0.22(-0.38$ to -0.05$)$ & 0.01 \\
\hline \multicolumn{5}{|l|}{ DASH score } \\
\hline Week 1 & $0.09 \quad(-1.65$ to 1.82$)$ & 0.36 ( -1.76 to 2.48$)$ & $-0.44(-3.09$ to 2.21$)$ & 0.8 \\
\hline Week 2 & $-1.45 \quad(-3.48$ to 0.58$)$ & $-0.54(-3.02$ to 1.94$)$ & $-1.11(-4.19$ to 1.97$)$ & 0.5 \\
\hline Week 5 & $-4.02(-6.48$ to -1.56$)$ & $-0.87(-3.92$ to 2.19$)$ & $-3.50(-7.16$ to 0.16$)$ & 0.06 \\
\hline Week 17 & $-7.75(-10.55$ to -4.95$)$ & $-1.53(-5.15$ to 2.09$)$ & $-6.72(-10.9$ to -2.57$)$ & $<0.01$ \\
\hline \multicolumn{5}{|c|}{ NRS on pain intensity } \\
\hline Week 1 & $-0.22 \quad(-0.68$ to 0.23$)$ & $-0.43(-0.89$ to 0.04$)$ & $-0.14(-0.40$ to 0.68$)$ & 0.6 \\
\hline Week 2 & $-0.30 \quad(-0.81$ to 0.21$)$ & $-0.50(-1.01$ to 0.01$)$ & $0.13(-0.46$ to 0.72$)$ & 0.7 \\
\hline Week 5 & $-0.68(-1.18$ to -0.19$)$ & $-0.55(-1.11$ to 0.02$)$ & $-0.22(-0.81$ to 0.36$)$ & 0.5 \\
\hline Week 17 & $-1.22(-1.79$ to -0.65$)$ & $-0.61(-1.22$ to 0.00$)$ & $-0.70(-1.34$ to -0.06$)$ & 0.03 \\
\hline \multicolumn{5}{|c|}{ SWMT sensation diameter at week $17, \mathrm{~mm}$} \\
\hline Thumb & $-0.29(-0.43$ to -0.14$)$ & $-0.17(-0.28$ to -0.06$)$ & $-0.05(-0.21$ to 0.11$)$ & 0.5 \\
\hline First finger & $-0.28(-0.41$ to -0.15$)$ & $-0.12(-0.22$ to -0.01$)$ & $-0.08(-0.22$ to 0.06$)$ & 0.3 \\
\hline Middle finger & $-0.28(-0.40$ to -0.15$)$ & $-0.13(-0.24$ to -0.01$)$ & $-0.11 \quad(-0.26$ to 0.04$)$ & 0.2 \\
\hline Little finger & $-0.15(-0.26$ to -0.03$)$ & $-0.14(-0.26$ to -0.03$)$ & $-0.02(-0.16$ to 0.12$)$ & 0.8 \\
\hline \multicolumn{5}{|c|}{ Time to complete DMMPUT at Week 17, s } \\
\hline Not blinded & $-2.11 \quad(-4.36$ to 0.13$)$ & $-0.80 \quad(-3.21$ to 1.61$)$ & $-1.87(-4.61$ to 0.88$)$ & 0.2 \\
\hline Blinded & $-6.50(-9.84$ to -3.15$)$ & $-0.32 \quad(-4.27$ to 3.63$)$ & $-6.13(-10.6$ to -1.63$)$ & $<0.01$ \\
\hline $\begin{array}{l}\text { Tip pinch } \\
\text { strength at } \\
\text { week 17, lb }\end{array}$ & $1.75 \quad(1.27$ to 2.22$)$ & $0.52 \quad(-0.02$ to 1.06$)$ & $1.17 \quad(0.48$ to 1.86$)$ & $<0.01$ \\
\hline $\begin{array}{l}\text { Note: } \mathrm{BCTQ}= \\
\text { Questionnaire, } \\
\text { numeric rating } \\
\text { *The estimate }\end{array}$ & $\begin{array}{l}\text { rpal Tunnel Questionnai } \\
T=\text { Dellon-modified Mol } \\
=\text { Symptom Severity Sca } \\
\text { changes in score and } p \text { va }\end{array}$ & $\begin{array}{l}\text { confidence interval, DA } \\
\text { k-up test, FSS = Functic } \\
\text { ИT = Semmes-Weinstei } \\
\text { scores between group }\end{array}$ & $\begin{array}{l}\text { isabilities of the Arm, } \\
\text { tus Scale, MD = mean } \\
\text { filament Test. }\end{array}$ & $\begin{array}{l}\text { and Hand } \\
\text { e, NRS }= \\
\text { ance. }\end{array}$ \\
\hline
\end{tabular}


(95\% CI -0.25 to 0.06 ) in the splinting treatment only group. The mean difference (MD) in change from baseline to week 17 between the 2 groups was -0.20 (95\% CI -0.36 to -0.03$)$. The cumulative distribution function for Symptom Severity Scale score reduction is shown in Appendix 3 (Figure 1, available at www.cmaj.ca/ lookup/suppl/doi:10.1503/cmaj.151003/-/DC1), with a vertical line denoting a MID threshold of 0.33 . Forty participants $(47.0 \%)$ in the elec-

Table 3: Participants with clinically important changes in outcomes, by follow-up time*

\begin{tabular}{|c|c|c|c|}
\hline \multirow[b]{2}{*}{ Outcome } & \multicolumn{2}{|c|}{ No. (\%) of participants } & \multirow[b]{2}{*}{$p \S$} \\
\hline & $\begin{array}{l}\text { Treatment group } \\
\text { (electroacupuncture } \\
\text { with nocturnal } \\
\text { splinting) } \\
n=90\end{array}$ & $\begin{array}{c}\text { Control group } \\
\text { (nocturnal } \\
\text { splinting only) } \\
n=91\end{array}$ & \\
\hline \multicolumn{4}{|l|}{ BCTQ score } \\
\hline \multicolumn{4}{|l|}{ SSS } \\
\hline Week 1 & $11(12.2)$ & 19 (20.9) & 0.1 \\
\hline Week 2 & $19(21.1)$ & $23(25.3)$ & 0.5 \\
\hline Week 5† & 33 (37.9) & $27(30.0)$ & 0.3 \\
\hline Week 17¥ & $40(47.1)$ & $32(36.0)$ & 0.1 \\
\hline \multicolumn{4}{|l|}{ FSS } \\
\hline Week 1 & $7(7.8)$ & $17(18.7)$ & 0.03 \\
\hline Week 2 & $15(16.7)$ & $15(16.5)$ & 1.0 \\
\hline Week 5t & $19(21.8)$ & $18(20.0)$ & 0.8 \\
\hline Week 17¥ & $30(35.3)$ & $21(23.6)$ & 0.09 \\
\hline \multicolumn{4}{|l|}{ DASH score } \\
\hline Week 1 & $7(7.8)$ & $16(17.6)$ & 0.05 \\
\hline Week 2 & $17(18.9)$ & $19(20.9)$ & 0.7 \\
\hline Week 5t & $24(27.6)$ & $21(23.3)$ & 0.5 \\
\hline Week 17¥ & $40(47.1)$ & $26(29.2)$ & 0.02 \\
\hline \multicolumn{4}{|c|}{ Pain intensity } \\
\hline Week 1 & $18(20.0)$ & $20(22.0)$ & 0.7 \\
\hline Week 2 & $21(23.3)$ & $24(26.4)$ & 0.6 \\
\hline Week 5t & $27(31.0)$ & $28(31.1)$ & 1.0 \\
\hline Week 17‡ & $34(40.0)$ & $31(34.8)$ & 0.5 \\
\hline \multicolumn{4}{|c|}{ Blinded DMMPUT completion time } \\
\hline Week 17‡ & $32(37.6)$ & $17(19.1)$ & $<0.01$ \\
\hline \multicolumn{4}{|c|}{ Tip pinch strength } \\
\hline Week 17¥ & $39(45.9)$ & $32(36.0)$ & 0.2 \\
\hline \multicolumn{4}{|c|}{$\begin{array}{l}\text { Note: BCTQ = Boston Carpal Tunnel Questionnaire, DASH = Disability of Hand and Shoulder } \\
\text { Questionnaire, DMMPUT = Dellon-modified Moberg pick-up test, FSS = Functional Status } \\
\text { Scale. } \\
\text { *Threshold for a minimally important difference is defined as a half of the baseline SD for } \\
\text { SSS, FSS, DASH and DMMPUT, } 1.66 \mathrm{lb} \text { for tip pinch strength, and } 2 \text { for pain intensity measured } \\
\text { on a numerical rating scale. } \\
\text { tParticpants left trial ( } n=87 \text { for the treatment group, } n=90 \text { for the control group). } \\
\text { \#Particpants left trial ( } n=85 \text { for the treatment group, } n=89 \text { for the control group). } \\
\text { STwo-sided } p \text { values for comparing proportions of patients showing clinically important } \\
\text { changes between groups. }\end{array}$} \\
\hline
\end{tabular}

troacupuncture combined with splinting treatment group achieved clinically important reduction in Symptom Severity Scale score compared with $32(36.0 \%)$ in the splinting treatment only group, but we found no significant difference $(p=0.1)$ (Table 3).

\section{Secondary outcomes and adverse events}

At week 17, patients in the electroacupuncture combined with splinting treatment group showed more improvement in Functional Status Scale score, Disabilities of the Arm, Shoulder and Hand Questionnaire score, pain, blinded Dellon-modified Moberg pick-up test score and maximal tip pinch strength compared with patients in the splinting treatment only group (Table 2). However, significant differences were only observed in scores for the Disabilities of the Arm, Shoulder and Hand Questionnaire $(p=0.02)$ and the blinded Dellon-modified Moberg pick-up test $(p<0.01)$ for the proportion of patients achieving clinically important improvement (Table 3). Cumulative distribution functions for these outcomes are shown in Appendix 3 (Figures 2-6). Adverse events from electroacupuncture were infrequent and mild. Detailed results on secondary outcomes and adverse events are found in Appendix 4 (available at www.cmaj.ca/lookup/suppl/ doi:10.1503/cmaj.151003/-/DC1).

\section{Interpretation}

\section{Main findings}

We found that treatment using electroacupuncture provided small improvements in symptoms, disability, function, dexterity and pinch strength among patients with chronic mild to moderate symptoms of primary carpal tunnel syndrome when combined with nocturnal splinting. Except for disability and dexterity, the proportion of patients who had clinically important benefit from treatment was not significantly different when comparing add-on electroacpuncture with splinting. The electroacupuncture protocol evaluated in this trial is a safe procedure that is easily replicable by trained acupuncturists.

Our data also suggest that splinting alone was inadequate for relieving symptoms and improving functions in this group of patients, because there were no significant improvements in any outcomes in the splinting treatment only group.

\section{Comparison with other studies}

Despite uncertainty on its effectiveness, wrist splinting is recommended as a first-line conservative treatment by several authorities, includ- 
ing the National Institute for Health and Care Excellence in the United Kingdom, ${ }^{41}$ American Academy of Orthopaedic Surgeons ${ }^{42}$ and the American College of Occupational and Environmental Medicine; ${ }^{43}$ however, no specific recommendation for or against acupuncture exists. This is in line with the mixed results from existing trials involving acupuncture for carpal tunnel syndrome.

\section{Limitations}

The positive effects of acupuncture observed based on outcomes reported by participants could be biased by participant expectancy and lack of blinding of participants in the study. Nevertheless, a systematic review suggested that the impact of patient expectancy on acupuncture outcome is uncertain, ${ }^{44}$ and a more recent study reported that baseline expectancy may not predict treatment response when electroacupuncture is applied. ${ }^{45}$ Although the impact of expectancy on patient-reported outcomes may be small in this trial, lack of patient blinding may still incur positive bias on effect size. ${ }^{46}$ Despite the lack of blinding and control for expectancy, the add-on benefits of electroacupuncture were seen in the assessorblinded objective outcomes (blinded Dellonmodified Moberg pick-up test and maximal tip pinch strength), which are known to be unaffected by a lack of patient blinding. ${ }^{47}$

We did not choose to add a sham control group for this trial because we wanted to determine the overall (specific effect of treatment with electroacupuncture and nonspecific effect of the whole treatment process) add-on benefit of electroacupuncture in a primary care setting where splinting is often used as a first-line treatment. From a pragmatic perspective, the nonspecific benefits of electroacupuncture characterized by patient-reported outcomes may be interpreted as clinical effect instead of bias. ${ }^{48,49}$

Another limitation is that the generalizability of the results may be limited because this trial was performed at a single centre. Also, we acknowledge that higher needle numbers and more frequent sessions may have a positive correlation with effect size..$^{50}$ Our results concur with the later observation as most outcomes in our study did not show significant benefits until week 17. However, it is uncertain that a different regimen of acupuncture (e.g., shorter intervention period) would provide a different effect. Finally, a lack of established MID values for some of the outcomes in this study may cause the interpretation of our results to vary when these MID values become available through an anchor- or consensus-based approach. ${ }^{51}$
Our study has several strengths, including a high compliance rate for electroacupuncture treatment $(100 \%)$ and wrist splinting (> 80\% in both groups). Included participants were mainly female, which reflects the prevalence pattern for carpal tunnel syndrome in the community. ${ }^{52,53}$

Because we recruited patients with a clear clinical diagnosis of carpal tunnel syndrome as set out by current guideline recommendations, we did not perform nerve conduction studies; this reflects routine practice in primary care settings.

Among patients with injuries to the upper extremity, the Katz diagram has a negative predictive value of $91 \%$ when the result does not indicate classic or probable diagnosis, ruling out a substantial portion of patients without carpal tunnel syndrome. ${ }^{23}$ If we assume a conservative prevalence of $50 \%$ of carpal tunnel syndrome in this sample, the positive and negative predictive values of wrist flexion and nerve compression tests were $94 \%$ and $87 \%$, respectively. ${ }^{27}$ Independent of prevalence, high-quality studies have shown that the Phalen manuever test and Tinel sign test have favourable diagnostic likelihood ratios (Phalen mean positive likelihood ratio 2.68 and mean negative likelihood ratio 0.54 ; Tinel mean positive likelihood ratio 2.95 and mean negative likelihood ratio 0.57). ${ }^{54}$ Therefore, we believe that the diagnostic criteria we used in this trial are satisfactory.

Diagnosis of carpal tunnel syndrome using ultrasonography has emerged as an alternative to nerve conduction studies and, because it has similar performance, a lower cost and higher patient acceptance,,$^{54}$ future trials may consider ultrasonography as an additional inclusion criterion.

We chose a 17 -week follow-up duration, which is in line with current guideline recommendations for conservative treatment. Nevertheless, observing the longer term impact of electroacupuncture would require extended research.

\section{Conclusion}

There is no current consensus on appropriate treatment for patients with chronic $(\geq 6 \mathrm{mo})$ mild to moderate symptoms of carpal tunnel syndrome. ${ }^{55}$ Most participants in our trial had chronic symptoms for more than 2 years, with moderate severity at enrolment. Our results showed the potential benefit of combining electroacupuncture with nocturnal splinting treatment for patients with chronic mild to moderate symptoms of longer duration. Indeed, the National Institute for Health and Care Excellence guideline recommends the use of steroid injection or surgery if conservative treatment fails to improve symptoms after 3 months. Use of steroid injections for treatment is not a com- 
mon practice in primary care settings in Hong Kong. In this trial, those patients who had received steroid injections were excluded. Future trials may want to evaluate the benefit of combining electroacupuncture treatment with steroid injections.

\section{References}

1. Martyn CN, Hughes RA. Epidemiology of peripheral neuropathy. J Neurol Neurosurg Psychiatry 1997;62:310-8.

2. Atroshi I, Gummesson C, Johnsson R, et al. Prevalence of carpal tunnel syndrome in a general population. JAMA 1999;282:153-8.

3. Lundborg G, Richard P. Bunge memorial lecture. Nerve injury and repair - a challenge to the plastic brain. J Peripher Nerv Syst 2003;8:209-26.

4. Rossignol M, Stock S, Patry L, et al. Carpal tunnel syndrome: What is attributable to work? The Montreal study. Occup Environ Med 1997;54:519-23.

5. Leigh JP, Miller TR. Job-related diseases and occupations within a large workers' compensation data set. Am J Ind Med 1998;33:197-211.

6. Burton C, Chesterton LS, Davenport G. Diagnosing and managing carpal tunnel syndrome in primary care. Br J Gen Pract 2014; 64:262-3.

7. Bland JD. Treatment of carpal tunnel syndrome. Muscle Nerve 2007:36:167-71.

8. Burke FD, Ellis J, McKenna H, et al. Primary care management of carpal tunnel syndrome. Postgrad Med J 2003;79: 433-7.

9. Taylor-Gjevre RM, Gjevre JA, Strueby L, et al. Treatments for carpal tunnel syndrome: Who does what, when ... and why? Can Fam Physician 2007;53:1186-90.

10. O'Connor D, Marshall S, Massy-Westropp N. Non-surgical treatment (other than steroid injection) for carpal tunnel syndrome. Cochrane Database Syst Rev 2003;(1):CD003219.

11. Marshall S, Tardif G, Ashworth N. Local corticosteroid injection for carpal tunnel syndrome. Cochrane Database Syst Rev 2007;(2):CD001554.

12. Atroshi I, Flondell M, Hofer M, et al. Methylprednisolone injections for the carpal tunnel syndrome: a randomized, placebo-controlled trial. Ann Intern Med 2013;159:309-17.

13. Berger M, Vermeulen M, Koelman JH, et al. The long-term follow-up of treatment with corticosteroid injections in patients with carpal tunnel syndrome. When are multiple injections indicated? J Hand Surg Eur Vol 2013;38:634-9.

14. Vahi PS, Kals M, Koiv L, et al. Preoperative corticosteroid injections are associated with worse long-term outcome of surgical carpal tunnel release. Acta Orthop 2014;85:102-6.

15. Sim H, Shin BC, Lee MS, et al. Acupuncture for carpal tunnel syndrome: a systematic review of randomized controlled trials. $J$ Pain 2011;12:307-14.

16. Yang CP, Hsieh CL, Wang NH, et al. Acupuncture in patients with carpal tunnel syndrome: a randomized controlled trial. Clin J Pain 2009;25:327-33.

17. Kumnerddee W, Kaewtong A. Efficacy of acupuncture versus night splinting for carpal tunnel syndrome: a randomized clinical trial. J Med Assoc Thai 2010;93:1463-9.

18. Yao E, Gerritz PK, Henricson E, et al. Randomized controlled trial comparing acupuncture with placebo acupuncture for the treatment of carpal tunnel syndrome. PM R 2012;4:367-73.

19. Khosrawi S, Moghtaderi A, Haghighat S. Acupuncture in treatment of carpal tunnel syndrome: A randomized controlled trial study. J Res Med Sci 2012;17:1-7.

20. Langevin HM, Schnyer R, MacPherson H, et al. Manual and electrical needle stimulation in acupuncture research: pitfalls and challenges of heterogeneity. J Altern Complement Med 2015; 21:113-28.

21. Zhang R, Lao L, Ren K, et al. Mechanisms of acupunctureelectroacupuncture on persistent pain. Anesthesiology 2014; 120:482-503

22. Katz JN, Stirrat CR. A self-administered hand diagram for the diagnosis of carpal tunnel syndrome. J Hand Surg Am 1990;15:360-3

23. Katz JN, Stirrat CR, Larson MG, et al. A self-administered hand symptom diagram for the diagnosis and epidemiologic study of carpal tunnel syndrome. J Rheumatol 1990;17:1495-8.

24. Franzblau A, Werner RA, Albers JW, et al. Workplace surveillance for carpal tunnel syndrome using hand diagrams. $J$ Occup Rehabil 1994;4:185-98.

25. Dale AM, Strickland J, Symanzik J, et al. Reliability of hand diagrams for the epidemiologic case definition of carpal tunnel syndrome. J Occup Rehabil 2008;18:233-48.

26. Rempel D, Evanoff B, Amadio PC, et al. Consensus criteria for the classification of carpal tunnel syndrome in epidemiologic studies. Am J Public Health 1998;88:1447-51.

27. Tetro AM, Evanoff BA, Hollstien SB, et al. A new provocative test for carpal tunnel syndrome. Assessment of wrist flexion and nerve compression. J Bone Joint Surg Br 1998;80:493-8.

28. Katz JN, Simmons BP. Clinical practice. Carpal tunnel syndrome. N Engl J Med 2002;346:1807-12.

29. Lewis C, Mauffrey C, Newman S, et al. Current concepts in carpal tunnel syndrome: a review of the literature. Eur $J$ Orthop Surg Traumatol 2010;20:445-52.

30. Efird J. Blocked randomization with randomly selected block sizes. Int J Environ Res Public Health 2011;8:15-20.

31. Saghaei M. Random allocation software for parallel group randomized trials. BMC Med Res Methodol 2004;4:26.

32. Doig GS, Simpson F. Randomization and allocation concealment: a practical guide for researchers. J Crit Care 2005;20:18791, discussion 191-3.

33. LeBlanc KE, Cestia W. Carpal tunnel syndrome. Am Fam Physician 2011;83:952-8.

34. Keulers BJ, Welters CF, Spauwen PH, et al. Can face-to-face patient education be replaced by computer-based patient education? A randomised trial. Patient Educ Couns 2007;67:176-82.

35. Gartsman GM, Kovach JC, Crouch CC, et al. Carpal arch alteration after carpal tunnel release. J Hand Surg Am 1986;11:372-4.

36. Keith MW, Masear V, Amadio PC, et al. Treatment of carpal tunnel syndrome. J Am Acad Orthop Surg 2009;17:397-405.

37. Levine DW, Simmons BP, Koris MJ, et al. A self-administered questionnaire for the assessment of severity of symptoms and functional status in carpal tunnel syndrome. J Bone Joint Surg Am 1993;75:1585-92.

38. Leite JC, Jerosch-Herold C, Song F. A systematic review of the psychometric properties of the Boston Carpal Tunnel Questionnaire. BMC Musculoskelet Disord 2006;7:78.

39. Hudak PL, Amadio PC, Bombardier C. Development of an upper extremity outcome measure: the DASH (Disabilities of the Arm, Shoulder and Hand). The Upper Extremity Collaborative Group (UECG) [published erratum in Am J Ind Med 1996;30:371]. Am J Ind Med 1996;29:602-8.

40. Mallouhi A, Pülzl P, Trieb T, et al. Predictors of carpal tunnel syndrome: accuracy of gray-scale and color Doppler sonography. AJR Am J Roentgenol 2006;186:1240-5.

41. National Institute for Health and Care Excellence. Carpal tunnel syndrome. London (UK): National Institue for Health and Care Excellence; 2012.

42. Management of carpal tunnel syndrome evidence-based clinical practice guideline. Rosemont (IL): American Academy of Orthopaedic Surgeons; 2016. Available: www.aaos.org/ctsguideline (accessed 2016 May 27)

43. Carpal tunnel syndrome. In: Hegmann KT, editor. Occupational medicine practice guidelines. Evaluation and management of common health problems and functional recovery in workers. 3rd ed. Elk Grove Village (IL): American College of Occupational and Environmental Medicine (ACOEM); 2011:1-73.

44. Colagiuri B, Smith CA. A systematic review of the effect of expectancy on treatment responses to acupuncture. Evid Based Complement Alternat Med 2012;2012:857804.

45. Bauml J, Xie SX, Farrar JT, et al. Expectancy in real and sham electroacupuncture: Does believing make it so? J Natl Cancer Inst Monogr 2014;2014:302-7.

46. Hróbjartsson A, Emanuelsson F, Skou Thomsen AS, et al. Bias due to lack of patient blinding in clinical trials. A systematic review of trials randomizing patients to blind and nonblind sub-studies. Int J Epidemiol 2014;43:1272-83.

47. Wood L, Egger M, Gluud LL, et al. Empirical evidence of bias in treatment effect estimates in controlled trials with different interventions and outcomes: meta-epidemiological study. BMJ 2008;336:601-5.

48. Witt CM, Aickin M, Baca T, et al. Effectiveness guidance document (EGD) for acupuncture research - a consensus document for conducting trials. BMC Complement Altern Med 2012;12:148.

49. Howick J, Friedemann C, Tsakok M, et al. Are treatments more effective than placebos? A systematic review and metaanalysis. PLoS One 2013;8:e62599.

50. MacPherson H, Maschino AC, Lewith G, et al. Characteristics of acupuncture treatment associated with outcome: an individual patient meta-analysis of 17,922 patients with chronic pain in randomised controlled trials. PLoS One 2013;8:e77438.

51. Revicki D, Hays RD, Cella D, et al. Recommended methods for determining responsiveness and minimally important differences for patient-reported outcomes. J Clin Epidemiol 2008;61:102-9 
52. Tanaka S, Wild DK, Seligman PJ, et al. The US prevalence of self-reported carpal tunnel syndrome: 1988 National Health Interview Survey data. Am J Public Health 1994;84:1846-8.

53. Atroshi I, Englund M, Turkiewicz A, et al. Incidence of physician-diagnosed carpal tunnel syndrome in the general population. Arch Intern Med 2011;171:943-4.

54. Valdes K, LaStayo P. The value of provocative tests for the wrist and elbow: a literature review. J Hand Ther 2013;26:32-42, quiz 43.

55. Huisstede BM, Fridén J, Coert JH, et al. Carpal tunnel syndrome: hand surgeons, hand therapists, and physical medicine and rehabilitation physicians agree on a multidisciplinary treatment guideline - results from the European HANDGUIDE Study. Arch Phys Med Rehabil 2014;95:2253-63.

Affiliations: Jockey Club School of Public Health and Primary Care (Chong, Chung, Griffiths, Ho, Sit, Liu, Wong, Yip, Zee); Hong Kong Institute of Integrative Medicine (Chung, Lau, Sit, Wong, Wu); Department of Medicine and Therapeutics (Lau, Wu); School of Chinese Medicine (Leung), The Chinese University of Hong Kong, Prince of Wales Hospital, Shatin, Hong Kong, China; Institute of Global Health Innovation (Griffiths), Imperial College London, London, UK
Contributors: Vincent Chung, Marc Chong, Albert Leung, Sian Griffiths, Benny Zee, Justin Wu, Regina Sit, Alexander Lau and Samuel Wong contributed substantially to conception and design of the article; Vincent Chung, Robin Ho and Siya Liu acquired the data; Vincent Chung, Robin Ho, Siya Liu, Marc Chong and Benjamin Yip analyzed and interpreted the data. All of the authors revised the article critically for important intellectual content, gave final approval of the version to be published and agreed to act as guarantors of the work.

Funding: This trial was funded by the Health and Health Services Research Fund, Hong Kong SAR Government (Reference no. 09100681). The funding source had no role in the design or conduct of the study; collection, management, analysis or interpretation of the data; preparation, review or approval of the manuscript; or decision to submit the manuscript for publication.

Data sharing: No data can be shared because of restrictions from the Health and Health Services Research Fund, Hong Kong SAR Government.

Acknowledgements: The authors thank Clifton Tam and Suey So for providing electroacupuncture services. 